This document is the Accepted Manuscript version of a Published Work that appeared in final form in ChemSoc.Rev, copyright (c) The Royal Society of Chemistry 2017 after peer review and technical editing by the publisher. To access the final edited and published work see: https://pubs.rsc.org/en/content/articlelanding/2017/ee/c7ee01553d\#!divAbstract

\title{
Ternary $\mathrm{Ni}-\mathrm{Co}-\mathrm{P}$ nanoparticles as noble-metal-free catalysts to boost the hydrolytic dehydrogenation of ammonia-borane $\dagger$
}

\author{
Chun-Chao Hou, $\ddagger^{\mathrm{ab}}$ Qiang Li, (DD $\ddagger^{\mathrm{c}}$ Chuan-Jun Wang, ${ }^{\mathrm{ab}}$ Cheng-Yun Peng, ${ }^{\text {ab }}$ \\ Qian-Qian Chen, ${ }^{a b}$ Hui-Fang Ye, ${ }^{a b}$ Wen-Fu Fu, ${ }^{\text {ad }}$ Chi-Ming Che, ${ }^{e}$ Núria López (DD *c \\ and Yong Chen (D)*ab
}

\begin{abstract}
The development of high-efficiency and low-cost catalysts for hydrogen release from chemical hydrogen-storage materials is essential for the hydrogen-economy paradigm. Herein, we report a facile and controllable method to fabricate a series of Co-doped nickel phosphides and their corresponding nanohybrids with graphene oxide (GO) as highly efficient, robust and noble-metal-free catalysts for ammonia borane hydrolysis. The incorporation of Co into $\mathrm{Ni}_{2} \mathrm{P}$ effectively optimizes the electronic structures of $\mathrm{Ni}_{2-x} \mathrm{Co}_{x} \mathrm{P}$ catalysts to enhance their interaction with $A B$ and simultaneously facilitate the hydroxyl activation of $A B$, resulting in the reduction of the reaction energy barrier and thus substantial improvement of the catalytic rate.
\end{abstract}

Hydrogen, a renewable clean and abundant energy vector, is well recognized as one of the most ideal candidates to replace conventional fossil fuels in the future, but this prospect meets some intractable obstacles including the storage, transportation and release of hydrogen for practical application due to its low boiling point and volumetric density under air conditions. ${ }^{1-4}$ The development of safe and efficient chemical storage and release of hydrogen under mild conditions is thus necessary for the sake of the well-known hydrogen-economy paradigm. ${ }^{5-9}$ Ammonia-borane (AB) which has the advantages of a low molecular weight but high hydrogen content (19.6 wt\%, $\left.146 \mathrm{~g} \mathrm{~L}^{-1}\right)$, long-term stability under ambient temperature, and non-toxicity, is regarded

\footnotetext{
${ }^{a}$ Key Laboratory of Photochemical Conversion and Optoelectronic Materials and HKU-CAS Joint Laboratory on New Materials Technical Institute of Physics and Chemistry, Chinese Academy of Sciences, Beijing 100190, P. R. China.

E-mail: chenyong@mail.ipc.ac.cn

${ }^{b}$ University of Chinese Academy of Sciences, Beijing 100049, P. R. China

${ }^{c}$ Institute of Chemical Research of Catalonia, ICIQ. The Barcelona Institute of Science and Technology, Av. Països Catalans, 16, 43007, Tarragona, Spain.

E-mail: nlopez@iciq.es

${ }^{d}$ College of Chemistry and Engineering, Yunnan Normal University,

Kunming 650092, P. R. China. E-mail: fuwf@mail.ipc.ac.cn

${ }^{e}$ State Key Laboratory of Synthetic Chemistry and Department of Chemistry,

The University of Hong Kong, Pokfulam Road, Hong Kong, P. R. China

$\dagger$ Electronic supplementary information (ESI) available. See DOI: 10.1039/c7ee01553d

\$ The authors contributed equally.
}

\begin{abstract}
Broader context
The chemical storage and release of hydrogen under mild conditions are of importance to the hydrogen-economy paradigm. Ammonia-borane (AB) has been regarded as a competitive candidate for chemical hydrogen storage because of its high hydrogen content, non-toxicity, and long-term stability under ambient temperature. Fast hydrogen evolution from $\mathrm{AB}$ has been achieved using noble metal nanoparticles (e.g. Rh and $\mathrm{Pt}$ ) as the catalyst. However, all non-noble metal catalysts (e.g. Fe, Co, Ni nanoparticles) still display relatively poor catalytic activity; the TOF is usually less than $70 \mathrm{~min}^{-1}$ at room temperature for these systems. Therefore, the development of highefficiency and noble-metal-free catalysts for hydrogen release is highly desirable. Metal phosphides with partial charge transfer from metal to $\mathrm{P}$ have been discovered to be promising catalysts for AB hydrolysis. However, the specific mechanism regarding how the electronic structure of metal phosphide influences the catalytic performance and why the presence of extra $\mathrm{OH}^{-}$can dramatically improve the activity are unclear. In this work, ternary Ni-Co-P nanoparticles with various metal elemental ratios and electronic structures are firstly used as catalysts for $\mathrm{AB}$ hydrolysis. The incorporation of $\mathrm{Co}$ into $\mathrm{Ni}_{2} \mathrm{P}$ effectively optimizes the electronic structures of $\mathrm{Ni}_{2-x} \mathrm{Co}_{x} \mathrm{P}$ catalysts to enhance their interaction with $\mathrm{AB}$ and simultaneously facilitate the hydroxyl activation of $\mathrm{AB}$, resulting in the reduction of the reaction energy barrier and thus substantial improvement of the catalytic rate.
\end{abstract}

as a competitive candidate for chemical hydrogen storage. ${ }^{10-12}$ Fast hydrogen evolution from $\mathrm{AB}$ has been achieved using homogeneous molecular systems and metallic nanoparticles (MNPs), especially Pt, Ru-based noble metals and/or their alloys, as the catalyst. ${ }^{13-16}$ However, the exorbitant prices and global reserve scarcity of these precious metals limit their extensive usage. It is highly required to develop robust and noble-metal-free catalysts with high and controllable activities which can operate under ambient conditions. ${ }^{17-20}$

In this respect, $\mathrm{Xu}$ and co-workers reported that low-cost MNPs (Ni, Co and $\mathrm{Cu}$ ) immobilized on various supports with ample surface areas showed good catalytic performances for $\mathrm{AB}$ hydrolysis in $2006 .{ }^{21}$ Following this, they found that amorphous Fe NPs generated in situ through reduction of $\mathrm{FeSO}_{4}$ by $\mathrm{NaBH}_{4}$ exhibited high catalytic activity, which overwhelmingly hinges on the aspects of morphology, dispersion, size and electronic structure. ${ }^{22}$ 
Quite recently, Zhong, Lee and co-workers developed a nanostructured $\mathrm{Cu}_{x} \mathrm{Co}_{1-x} \mathrm{O} / \mathrm{GO}$ bi-metallic synergistic system to verify that the catalytic activity largely depends on the electronic structure changes in the metal nanoparticles (MNPs). ${ }^{23}$ Through the in situ XAS experiments, they managed to find that by screening the ratio of $\mathrm{Cu}-\mathrm{Co}$ in the MNPs deposited on GO, the $\mathrm{B}-\mathrm{N}$ bond in $\mathrm{AB}$ could be weakened due to the interaction of the modified surface of the catalysts with $\mathrm{AB}$, which eventually accelerates the hydrolysis of $\mathrm{AB}$ but is still suboptimal with respect to widespread applications. It has become the general trend, even though still a daunting challenge, to develop highly efficient catalysts through regulation of their electronic structures to facilely adsorb and weaken the B-N bonds. ${ }^{24-27}$

Recently, metal phosphide NPs with suitable charge transfer from metal to P facilitating the Proton-Coupled Electron Transfer (PCET) process have been widely used as photo- and electrocatalysts for water splitting. ${ }^{28-31}$ In light of the above unique feature and their high chemical stability over a wide range of $\mathrm{pH} 0-14, \mathrm{Ni}_{2} \mathrm{P}$ NPs were firstly applied to $\mathrm{AB}$ hydrolysis by our group and achieved a moderate TOF at room temperature. ${ }^{32}$ However, the specific mechanism regarding how the electronic structure of metal phosphide influences the catalytic performance and why the presence of extra $\mathrm{OH}^{-}$could dramatically improve the activity was unclear. With this in mind, herein we firstly use ternary $\mathrm{Ni}-\mathrm{Co}-\mathrm{P}$ nanoparticles with various metal elemental ratios and electronic structures as catalysts for $\mathrm{AB}$ hydrolysis in order to deeply understand the electronic structure-catalytic activity relationship of metal phosphides and thus to further promote their catalytic performance. Among the $\mathrm{Ni}_{2-x} \mathrm{Co}_{x} \mathrm{P}$ catalysts, the optimized $\mathrm{Ni}_{0.7} \mathrm{Co}_{1.3} \mathrm{P}$ displays the best catalytic performance with an initial TOF value of $58.4 \mathrm{~mol}\left(\mathrm{H}_{2}\right) \operatorname{mol}\left(\mathrm{Ni}_{0.7} \mathrm{Co}_{1.3} \mathrm{P}\right)^{-1} \mathrm{~min}^{-1}$ at ambient temperature. Furthermore, when $\mathrm{Ni}_{0.7} \mathrm{Co}_{1.3} \mathrm{P}$ was uniformly distributed on GO as a hybrid catalyst, an unprecedentedly high TOF value of $153.9 \mathrm{~mol}\left(\mathrm{H}_{2}\right) \operatorname{mol}\left(\mathrm{Ni}_{0.7} \mathrm{Co}_{1.3} \mathrm{P}\right)^{-1} \mathrm{~min}^{-1}$ for $\mathrm{AB}$ hydrolysis was achieved under ambient conditions. As far as we know, this TOF value is the highest one ever reported for noble-metal-free heterogeneous systems. This superior catalytic performance can be ascribed to collective factors including the ternary $\mathrm{Ni}-\mathrm{Co}-\mathrm{P}$ synergistic effect, high dispersibility, improved surface area and the interfacial interaction between $\mathrm{Ni}_{0.7} \mathrm{Co}_{1.3} \mathrm{P}$ and GO. The experimental results and mechanistic interpretation presented here are expected to stimulate further research efforts on metal phosphides for $\mathrm{AB}$ hydrolysis in the future.

The clean-surface $\mathrm{Ni}_{2-x} \mathrm{Co}_{x} \mathrm{P} \mathrm{NP}$ catalysts were prepared using a facile two-step strategy without addition of strong reducing agents like $\mathrm{NaBH}_{4}$ and organic stabilizers (Fig. S1, ESI $\dagger$ ). First, the $\mathrm{Ni}_{1-0.5 x} \mathrm{Co}_{0.5 x}(\mathrm{OH})_{2}$ precursors were obtained through a co-precipitation method by virtue of the similar $K_{\mathrm{sp}}$ of $\mathrm{Co}(\mathrm{OH})_{2}$ and $\mathrm{Ni}(\mathrm{OH})_{2}$. Then, the precursors were converted into ternary Co-Ni-P nanohybrids via a solid-state phosphorization reaction. When $\mathrm{Ni}(\mathrm{OH})_{2}$ alone was used as the precursor, the XRD analysis indicates the formation of the hexagonal phase of $\mathrm{Ni}_{2} \mathrm{P}$ (JCPDS No. 65-3544) (Fig. S2 and S3, ESI $\dagger$ ). With the increase of the Co-doping content, the positions of the XRD peaks shift toward higher diffraction angles corresponding to hexagonal NiCoP (JCPDS No. 71-2336), suggesting successful Co-doping into the

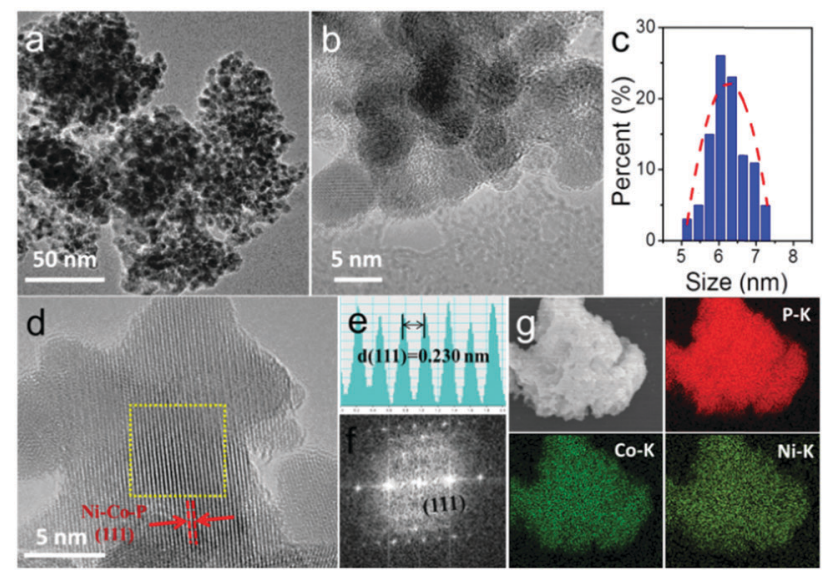

Fig. 1 (a) TEM and (b) magnified TEM images of the as-prepared $\mathrm{Ni}_{0.7} \mathrm{Co}_{1.3} \mathrm{P}$ nanoparticles. (c) The size distribution diagram. (d) The HRTEM image, (e) the spacing of the crystal lattice, (f) the FFT pattern of the corresponding area in (d), and (g) the corresponding EDX elemental mapping of $\mathrm{Co}, \mathrm{Ni}$ and $\mathrm{P}$ for the $\mathrm{Ni}{ }_{0.7} \mathrm{Co}_{1.3} \mathrm{P}$

lattice of $\mathrm{Ni}_{2} \mathrm{P}$. Note that the XRD profiles are exactly the same as NiCoP when the $x$ value is larger than 1.0. It has been reported that Co-Ni-P solid solutions, NiCoP (ICDD No. 04-001-4562), $\mathrm{Co}_{1.49} \mathrm{Ni}_{0.51} \mathrm{P}$ (ICDD No. 04-019-5182), $\mathrm{Co}_{1.4} \mathrm{Ni}_{0.6} \mathrm{P}$ (ICDD No. 04-005-5616) and others, ${ }^{33-35}$ all show very similar XRD patterns probably due to their same crystal structures and very similar lattice parameters.

TEM and magnified TEM images of $\mathrm{Ni}_{0.7} \mathrm{Co}_{1.3} \mathrm{P}$ (Fig. 1a and $\mathrm{b}$ ) reveal the formation of well-distributed sphere-shaped nanoparticles with a diameter of 5-7 nm. The HRTEM image taken for one $\mathrm{Ni}_{0.7} \mathrm{Co}_{1.3} \mathrm{P}$ nanocrystal reveals distinct lattice fringes with a spacing of about $0.230 \mathrm{~nm}$ corresponding to the (111) plane of $\mathrm{Ni}_{0.7} \mathrm{Co}_{1.3} \mathrm{P}$ (Fig. $1 \mathrm{~d}$ and e), which is consistent with the SAED pattern (Fig. 1f). The presence of $\mathrm{Ni}$, Co and $\mathrm{P}$ elements is confirmed by energy-dispersive X-ray spectroscopy (EDX) (Fig. S4, ESI $\dagger$ ) and inductively coupled plasma-optical emission spectroscopy (ICP-OES). The latter also enabled the accurate elemental analysis of the as-prepared samples (Table S1, ESI $\dagger$ ). As evidenced by the corresponding EDX elemental mappings, the $\mathrm{Ni}$, Co and $\mathrm{P}$ elements are uniformly distributed throughout the $\mathrm{Ni}_{0.7} \mathrm{Co}_{1.3} \mathrm{P}$ nanocrystals (Fig. 1g). The chemical states of $\mathrm{Ni}$, Co and $\mathrm{P}$ for $\mathrm{Ni}_{0.7} \mathrm{Co}_{1.3} \mathrm{P}$ are further characterized by X-ray photoelectron spectroscopy (XPS). As shown in Fig. S5 (ESI $\dagger$ ), two peaks are apparent in the $\mathrm{Ni}(2 \mathrm{p})$ region at 853.7 and $856.6 \mathrm{eV}$ and the Co (2p) region at 779.0 and $781.9 \mathrm{eV}$, respectively, along with another two peaks in the $\mathrm{P}(2 \mathrm{p})$ region at 129.7 and $133.7 \mathrm{eV}$. The peaks at 853.7, 779.0 and $129.7 \mathrm{eV}$ are attributed to the binding energies (BEs) for Ni, Co and $\mathrm{P}$ of $\mathrm{Ni}_{0.7} \mathrm{Co}_{1.3} \mathrm{P}$, respectively. The peaks at about 856.6, 781.9 and $133.7 \mathrm{eV}$ are assigned to the oxidized $\mathrm{Ni}$, Co and $\mathrm{P}$ species, resulting from inevitable surface oxidation of $\mathrm{Ni}_{0.7} \mathrm{Co}_{1.3} \mathrm{P}^{36-38}$

The $\mathrm{H}_{2}$-generating reaction by hydrolysis of $\mathrm{AB}$ with various $\mathrm{Ni}-\mathrm{Co}-\mathrm{P}$ catalysts was carefully evaluated under ambient conditions in a sealed home-made flask equipped with a magnetic stirrer. Control experiments showed that in the absence of catalysts, the $\mathrm{AB}$ aqueous solution has long-term stability without any $\mathrm{H}_{2}$ release. 
As shown in Fig. $2 \mathrm{a}$ and $\mathrm{b}$, the $\mathrm{Ni}_{0.7} \mathrm{Co}_{1.3} \mathrm{P}$ catalyst demonstrated the highest activity for hydrogen release from $\mathrm{AB}$ amongst a series of Ni-Co-P catalysts. The generated $\mathrm{H}_{2}$ gas was identified using gas chromatography (Fig. S6, ESI $\dagger$ ) and was monitored by a water-filled burette. All the hydrolysis experiments approximately generated 3 mole of $\mathrm{H}_{2}$ gas per mole of $\mathrm{AB}$, indicating that the decomposition of $\mathrm{AB}$ proceeded according to reaction (1) (see ref. 39):

$$
\mathrm{H}_{3} \mathrm{NBH}_{3}+4 \mathrm{H}_{2} \mathrm{O} \rightarrow \mathrm{NH}_{4}^{+}+\mathrm{B}(\mathrm{OH})_{4}^{-}+3 \mathrm{H}_{2}
$$

This process was further confirmed by ${ }^{1} \mathrm{H}$ NMR and ${ }^{11} \mathrm{~B}$ NMR spectra before and after the reaction (Fig. S7-S10, ESI $\dagger$ ). Then the effects of $\mathrm{Ni}_{2-x} \mathrm{Co}_{x} \mathrm{P}$ catalysts, the amount of $\mathrm{AB}$ and temperature on the hydrogen-generating rate were measured to interpret the kinetics of $\mathrm{AB}$ hydrolysis. As shown in Fig. $2 \mathrm{c}$ and Fig. S11-S13 (ESI $\dagger$ ), upon varying the molar ratio of $\mathrm{Ni}_{0.7} \mathrm{Co}_{1.3} \mathrm{P} / \mathrm{AB}$ by changing either the catalyst or the $\mathrm{AB}$ concentration, we found that the hydrogen-generating rate is dependent on $\left[\mathrm{Ni}_{0.7} \mathrm{Co}_{1.3} \mathrm{P}\right]$, following first-order kinetics with respect to catalyst concentration (Fig. S11, ESI $\dagger$ ). In contrast, the reaction rate is much less dependent on $[\mathrm{AB}]$ (Fig. S13, ESI $\dagger$ ), but nevertheless it does not follow zero-order kinetics due to the interactions between the catalysts and $\mathrm{OH}^{-} / \mathrm{H}_{2} \mathrm{O}$. The $\mathrm{Ni}_{0.7} \mathrm{Co}_{1.3} \mathrm{P}$ catalyst at an optimized cat/AB molar ratio of 0.026 displays the highest catalytic activity
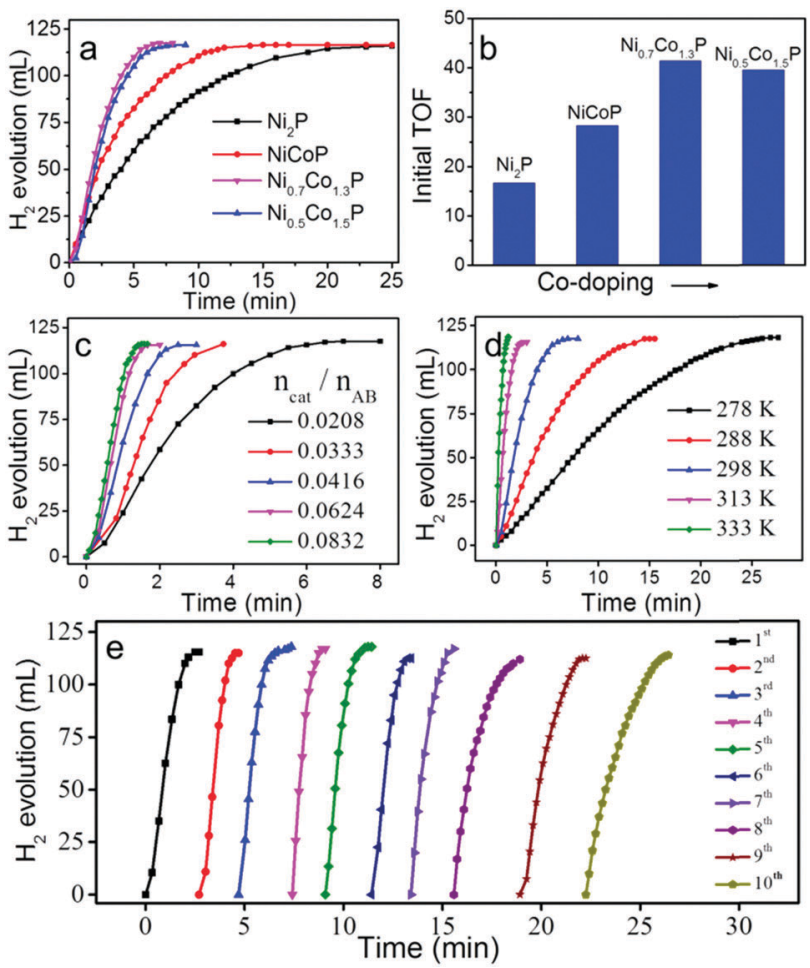

Fig. 2 (a) Stoichiometric hydrogen evolution in $0.5 \mathrm{M} \mathrm{NaOH}$ solution $\left(5 \mathrm{~mL}\right.$ ) containing $1.62 \mathrm{mmol} \mathrm{AB}$ catalyzed by $\mathrm{Ni}_{2} \mathrm{P}, \mathrm{NiCoP}, \mathrm{Ni}_{0.7} \mathrm{Co}_{1.3} \mathrm{P}$ and $\mathrm{Ni}_{0.5} \mathrm{CO}_{1.5} \mathrm{P}$ nanoparticles at $298 \mathrm{~K}$. (b) The corresponding TOFs. (c) The relationship between the $\mathrm{H}_{2}$ generation rate and $\mathrm{Ni}_{0.7} \mathrm{CO}_{1.3} \mathrm{P} / \mathrm{AB}$ ratios and (d) temperature. (e) Recycling of the $\mathrm{Ni}_{0.7} \mathrm{Co}_{1.3} \mathrm{P}$ catalyst $(10 \mathrm{mg})$ in $0.5 \mathrm{M}$ $\mathrm{NaOH}$ solution $(5 \mathrm{~mL})$, with addition of $\mathrm{AB}(1.62 \mathrm{mmol})$ to the system at $298 \mathrm{~K}$ in each cycle. with an initial TOF value of $58.4 \mathrm{~mol}_{\left(\mathrm{H}_{2}\right)} \operatorname{mol}_{\left(\mathrm{Ni}_{0.7} \mathrm{Co}_{1.3} \mathrm{P}\right)}{ }^{-1} \mathrm{~min}^{-1}$ at ambient temperature.

As shown in Fig. 2d and Fig. S14 (ESI $\dagger$ ), we also investigated the temperature dependence of the catalytic reaction in the range of $278-333 \mathrm{~K}$. The activation energy is estimated to be $43.2 \mathrm{~kJ} \mathrm{~mol}^{-1}$ through an Arrhenius plot. This value is favourably comparable to those of Ru-based bimetallic catalysts. ${ }^{40,41}$ The durability of this catalyst is further tested under ambient atmosphere at $298 \mathrm{~K}$. As depicted in Fig. $2 \mathrm{e}$, the $\mathrm{Ni}_{0.7} \mathrm{Co}_{1.3} \mathrm{P}$ catalyst retained $95.2 \%$ of its initial activity even after 7 cycles and still kept good activity after 10 cycles, demonstrating its good recyclability. The slight drop in activity might be ascribed to the aggregation of NPs, degraded crystallinity and inevitable surface oxidation during repeated experimental operations (Fig. S15, ESI $\dagger$ ).

To get an in-depth understanding of the improved catalytic performance of ternary Ni-Co-P catalysts, X-ray photoelectron spectroscopy (XPS) and X-ray absorption fine structure spectroscopy (XAFS) measurements were performed. Fig. S16 (ESI $\dagger$ ) shows XPS spectra of $\mathrm{Ni}_{2-x} \mathrm{Co}_{x} \mathrm{P}$ in the Co $2 \mathrm{p}$, Ni $2 \mathrm{p}$ and $\mathrm{P} 2 \mathrm{p}$ windows. It is clear that the BEs of both $\mathrm{Ni} 2 \mathrm{p}$ and Co $2 \mathrm{p}$ positively shift with the increase of Co-doping concentration, whereas the one of $\mathrm{P} 2 \mathrm{p}$ shifts negatively. These findings indicate that more charge transfer from metal to $\mathrm{P}$ centres occurred. The variation of electronic states can be further corroborated by the XAFS results. As shown in Fig. 3a, the Ni K-edge XANES spectra of all Ni-Co-P solid solutions are broadly similar to a distinct pre-edge peak that is characteristic of metal phosphides and differs from the pure $\mathrm{Ni}$ foil or $\mathrm{NiO}_{x}{ }^{42-44}$

However, with the increase of Co-doping content into $\mathrm{Ni}_{2} \mathrm{P}$, both the Ni absorption edge of XANES (Fig. $3 \mathrm{a}$ and b) and the Co K-edge (Fig. S17, ESI $\dagger$ ) slightly shifted toward higher energy, indicating a change in the average $\mathrm{Ni}$ and Co oxidation state to a higher value. Furthermore, the arrow in Fig. $3 \mathrm{~b}$ shows a clear shift in absorption intensity $(\mu t)$ with the increase of Co-doping. ${ }^{45-47}$ As the white line is indicative of the unoccupied electronic states, the increment of the white line peak at about $8350 \mathrm{eV}$ indicates the increase of unoccupied electronic states, which could be achieved by weak oxidation and in other words, electron transfer occurs from Ni to P centres. A similar situation is also observed in Co K-edge XANES spectra as shown in Fig. S17 (ESI $\dagger$ ). Based on the above discussions, we are convinced that charge transfer from metal to $\mathrm{P}$ centres occurred. Indeed the DFT calculations show a $\mathrm{P}$ charge in the range of -0.35 to $-0.42\left|e^{-}\right|$ (see Table S2, ESI $\dagger$ ).

The Ni K-edge extended XAFS (EXAFS) $k^{3} \chi(k)$ oscillation curve for the $\mathrm{Ni}_{0.7} \mathrm{Co}_{1.3} \mathrm{P}$ is comprised of an oscillation region in $2.5-8 \AA^{-1}$ due to the Ni-P contribution and another one beyond $8 \AA^{-1}$ assigned to the Ni-Ni contribution (Fig. 3c). This profile reveals a noticeable difference in comparison to that of $\mathrm{Ni}_{2} \mathrm{P}$, implying the structural difference in the coordination environment surrounding the $\mathrm{Ni}$ atoms. ${ }^{42-44} \mathrm{~A}$ similar situation can be found for a Co atom (Fig. S16, ESI $\dagger$ ), which coordinately provides evidence for the successful Co-incorporation. The $\mathrm{R}$ space plot for the Ni-Co-P NPs is characterized by two main peaks centred at $1.78 \AA$ and $2.20 \AA$, which roughly correspond to 

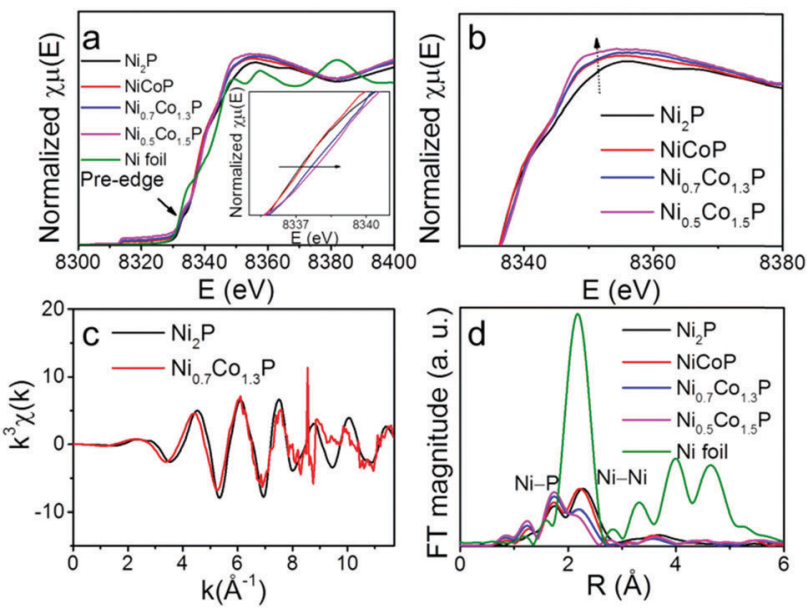

Fig. 3 (a) $\mathrm{Ni} \mathrm{K}$-edge and (b) magnified XANES spectra of $\mathrm{Ni}_{2} \mathrm{P}, \mathrm{NiCoP}$ $\mathrm{Ni}_{0.7} \mathrm{CO}_{1.3} \mathrm{P}$ and $\mathrm{Ni}_{0.5} \mathrm{CO}_{1.5} \mathrm{P}$ nanocatalysts. (c) Ni K-edge EXAFS $k^{3} \chi(k)$ oscillation functions of the $\mathrm{Ni}_{2} \mathrm{P}$ and $\mathrm{Ni}_{0.7} \mathrm{Co}_{1.3} \mathrm{P} \mathrm{NPs}$ and $(\mathrm{d})$ the corresponding FT curves of $\mathrm{Ni}_{2} \mathrm{P}, \mathrm{NiCoP}, \mathrm{Ni}_{0.7} \mathrm{Co}_{1.3} \mathrm{P}, \mathrm{Ni}_{0.5} \mathrm{CO}_{1.5} \mathrm{P}$ NPs and pure $\mathrm{Ni}$ foil for comparison (inset: the magnified curves of the $\mathrm{Ni}-\mathrm{Co}-\mathrm{P}$ solid solution).

the Ni-P and neighbouring Ni-Ni configurations, respectively. Compared to $\mathrm{Ni}$ foil, the Ni-Co-P NPs all showed decreased intensity, which was ascribed to the nano-size effect. As for Co-doping, the phase-shift-free Fourier transform (FT) showed an increased intensity of $\mathrm{Ni}-\mathrm{P}$ and a decrease in the $\mathrm{Ni}-\mathrm{Ni}$ feature together with slight phase changes, implying that the Co-doping induces a relatively higher coordination number of $\mathrm{Ni}-\mathrm{P}$ and a smaller coordination number of the second pair (Ni-Ni). ${ }^{48}$ All of these results revealed that Co was successfully incorporated into the crystal lattice of $\mathrm{Ni}_{2} \mathrm{P}$ and occupied partially the initial place of $\mathrm{Ni}$ atoms, implying the formation of a Co-P bond with decreasing long-range order.

The aforementioned results provide strong evidence for the promotion of electron transfer from metal to $\mathrm{P}$ centres in these ternary $\mathrm{Ni}-\mathrm{Co}-\mathrm{P}$ solutions, finally resulting in strong adsorption of $\mathrm{AB}$, which can effectively activate the $\mathrm{B}-\mathrm{N}$ bonds in $\mathrm{AB}$, therefore decreasing the reaction energy barrier and accelerating hydrogen evolution. This point was further corroborated by DFT modeling with the PBE functional. ${ }^{49}$ The specific details are provided in the ESI $\dagger$ and Tables S3-S6. In view of the basic reaction conditions where the reaction takes place, an $\mathrm{S}_{\mathrm{N}} 2$ mechanism where surface $\mathrm{OH}^{*}$ attacks the adsorbed $\mathrm{BH}_{3} \mathrm{NH}_{3}$ was found (Fig. 4, Scheme S1 and Table S4, ESI $\dagger$ ). As shown in the energy profile, the reaction starts from both $\mathrm{AB}$ and $\mathrm{H}_{2} \mathrm{O}$ adsorbed on the surface of the catalyst. This adsorption process is exothermic by $1.75 \mathrm{eV}$ for $\mathrm{NiCo}_{2} \mathrm{P}_{2}$, and only $1.23 \mathrm{eV}$ for $\mathrm{Ni}_{3} \mathrm{P}_{2}$, indicating the stronger interaction between them (solvent contributions would reduce adsorption by about $0.65 \mathrm{eV}) .^{50}$ The results are consistent with XPS and XAFS results.

Following the $\mathrm{S}_{\mathrm{N}} 2$ reaction in which surface $\mathrm{OH}^{*}$ attacks the $\mathrm{BH}_{3}$ group, $\mathrm{B}-\mathrm{N}$ bond breaking is induced $\left(\mathrm{OH}^{*}+\mathrm{BH}_{3} \mathrm{NH}_{3}{ }^{*} \rightarrow\right.$ $\mathrm{BH}_{3} \mathrm{OH}^{*}+\mathrm{NH}_{3}^{*}$, see video $\mathrm{S}_{\mathrm{N}} 2$.avi, ESI $\dagger$ ). This reaction is exothermic on $\mathrm{Ni}_{3} \mathrm{P}_{2}$ and $\mathrm{NiCo}_{2} \mathrm{P}_{2}$ by -0.20 and $-0.62 \mathrm{eV}$, respectively, showing that the doped system is more thermodynamically favourable. From the kinetic point of view, the reaction barrier on the doped

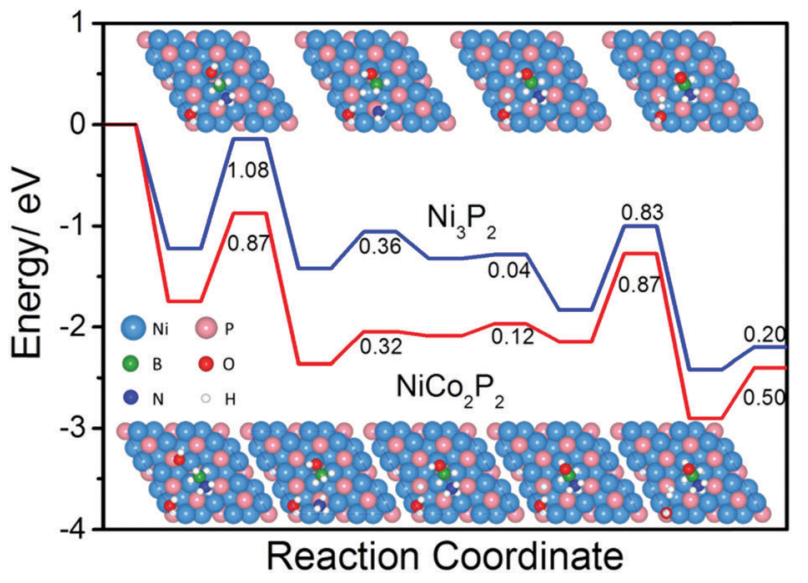

Fig. 4 Energy profiles of $A B$ hydrolytic dehydrogenation on $\mathrm{Ni}_{3} \mathrm{P}_{2}(0001)$ and $\mathrm{NiCO}_{2} \mathrm{P}_{2}(0001)$ surfaces with the same initial hydroxyl concentration. The 3D models in the upper panels denote transition states, while those at the bottom correspond to the intermediates.

surface is also favoured as the barrier on $\mathrm{NiCo}_{2} \mathrm{P}_{2}(0.87 \mathrm{eV})$ is $0.21 \mathrm{eV}$ lower than that on $\mathrm{Ni}_{3} \mathrm{P}_{2}(1.08 \mathrm{eV})$. The product, $\mathrm{BH}_{3} \mathrm{OH}^{*}$ has been widely regarded as the key intermediate in borohydride and ammonia borane oxidation reactions. ${ }^{51}$ After $\mathrm{B}-\mathrm{N}$ bond scission, one of the hydrides leaves the $\mathrm{B}$ atom with small barriers (0.36 and $0.32 \mathrm{eV})\left(\mathrm{BH}_{3} \mathrm{OH}^{*} \rightarrow \mathrm{BH}_{2} \mathrm{OH}^{*}+\mathrm{H}^{*}\right.$, see video $\mathrm{B}-\mathrm{H}$ bond-breaking.avi, $\mathrm{ESI} \dagger$ ) on both surfaces and this is then followed by the almost barrierless $\mathrm{B}-\mathrm{N}$ bond regeneration $(0.04$ and $0.12 \mathrm{eV})\left(\mathrm{BH}_{2} \mathrm{OH}^{*}+\mathrm{NH}_{3}{ }^{*} \rightarrow \mathrm{HOBH}_{2}-\mathrm{NH}_{3}{ }^{*}\right.$, see video $\mathrm{B}-\mathrm{N}$ regeneration.avi, ESI $\dagger$ ). A second $\mathrm{S}_{\mathrm{N}} 2$ cycle was calculated, $\mathrm{HOBH}_{3}{ }^{*}+\mathrm{OH}^{*} \rightarrow \mathrm{BH}_{2}(\mathrm{OH})_{2}{ }^{*}+\mathrm{H}^{*}$, and the higher barrier required $(1.01 \mathrm{eV})$ shows that this step cannot compete with the direct $\mathrm{B}-\mathrm{H}$ bond breaking from $\mathrm{BH}_{3} \mathrm{OH}^{*}$. In the $\mathrm{B}-\mathrm{N}$ bond formation step, electrostatic interaction between $\mathrm{B}$ and $\mathrm{N}$ atoms would contribute to the low $\mathrm{B}-\mathrm{N}$ bond regeneration barrier. Bader charge analysis ${ }^{52}$ (Table S5, ESI $\dagger$ ) shows that B and $\mathrm{N}$ atoms are positively and negatively charged by 1.26 and $1.20\left|e^{-}\right|$in $\mathrm{BH}_{2} \mathrm{OH}$ and $\mathrm{NH}_{3}$. Possible side reactions were also calculated (Table S4, ESI $\dagger$ ) but they cannot compete with this step. The hydride group on the surface can then attack $\mathrm{H}_{2} \mathrm{O}$ to generate $\mathrm{H}_{2}$ (see video $\mathrm{H}_{2} \mathrm{O}$ splitting.avi, ESI $\dagger$ ). The barriers of this step are close to each other for the two surfaces ( 0.83 and $0.87 \mathrm{eV}$ ), and the process is slightly more exothermic (by $0.17 \mathrm{eV}$ ) on the Co-containing one. The last step concerns $\mathrm{H}_{2}$ desorption which is slightly easier on $\mathrm{Ni}_{2} \mathrm{P}$ but the energies for desorption are low and will be surpassed by the molecular entropy gain. After one reaction cycle $\left(\mathrm{BH}_{3} \mathrm{NH}_{3}+\mathrm{H}_{2} \mathrm{O} \rightarrow \mathrm{HOBH}_{2} \mathrm{NH}_{3}+\mathrm{H}_{2}\right)$, when the species left on the surface are $\mathrm{HOBH}_{2}-\mathrm{NH}_{3}$, it will repeat the previous steps twice and produce two more $\mathrm{H}_{2}$ molecules from $\mathrm{BH}_{2}(\mathrm{OH})_{2}{ }^{*}$ and $\mathrm{BH}(\mathrm{OH})_{3}{ }^{*}$. These species and their importance in reaction mechanisms have been proposed by Chatenet et al. via in situ Fourier transform infrared spectroscopy studies on borohydride ${ }^{53}$ and ammonia borane oxidation reactions. ${ }^{54}$ Our mechanism based on DFT matches well with these results. We should note that the $\mathrm{S}_{\mathrm{N}} 2$ step is the ratelimiting step in $\mathrm{AB}$ hydrolytic dehydrogenation, which could rationalize the common phenomenon that the presence of $\mathrm{OH}^{-}$ 


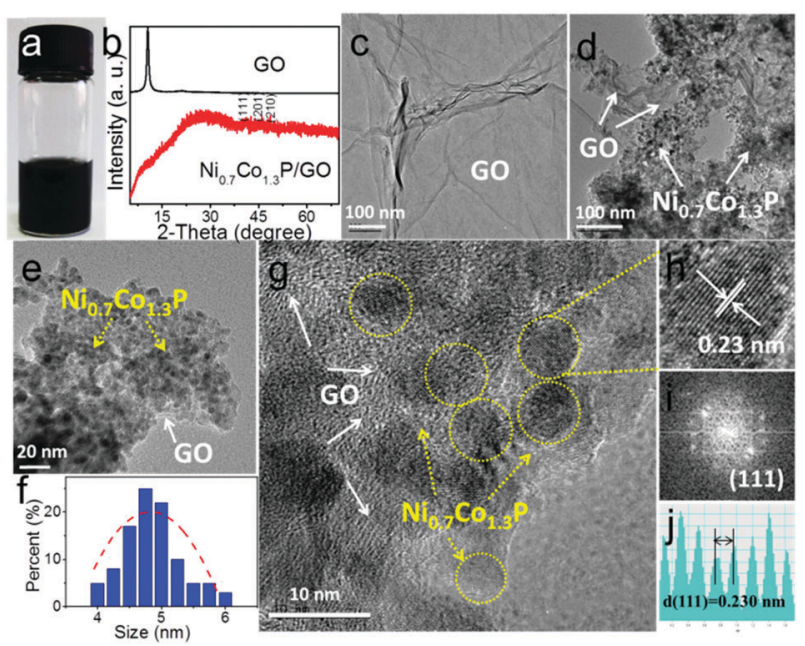

Fig. 5 (a) The photograph of $\mathrm{Ni}_{0.7} \mathrm{Co}_{1.3} \mathrm{P} / \mathrm{GO}$ dispersed in water. (b) XRD patterns. The TEM images of (c) $\mathrm{GO}$ and (d) the $\mathrm{Ni}_{0.7} \mathrm{CO}_{1.3} \mathrm{P} / \mathrm{GO}$ nanohybrid. (e) The magnified TEM and (g) HRTEM images of $\mathrm{Ni}_{0.7} \mathrm{Co}_{1.3} \mathrm{P} / \mathrm{GO}$. (f) The size distribution. (h) The single NPs, (i) the FFT pattern of the corresponding area in (h) and (j) the spacing of the crystal lattice.

could dramatically improve the catalytic properties and shorten the induction period. The lower barrier on the Co-containing surface explains why TOF values are higher for these materials. The observed improvement in the catalytic activity implies the fine tuning of the electronic structure at the Ni-Co surface as can be inspected from the d-band center position (see Table S6, $\mathrm{ESI} \dagger$ ). In the Ni-Co system the $\mathrm{Ni}$ centres are slightly more reactive than the Ni-only counterpart while the Co $d$-states are slightly less reactive than the Co-only compound. Thus the formation of the intermetallic bond is crucial for adjusting the chemical properties of the surface.

In an effort to further improve the catalytic activity, a $\mathrm{Ni}_{0.7} \mathrm{Co}_{1.3} \mathrm{P} / \mathrm{GO}$ nanohybrid material was prepared according to a modified procedure (see the ESI $\dagger$ ). As displayed in the TEM images in Fig. 5 and Fig. S18-S20 (ESI $\dagger$ ), $\mathrm{Ni}_{0.7} \mathrm{Co}_{1.3} \mathrm{P}$ NPs with a size of about $5 \mathrm{~nm}$ is uniformly deposited on the surface of GO due to the anchoring effect of the oxide-GO. The formation of the hybrid material is further confirmed by XRD, ICP-OES, XPS and BET (Fig. S21, S22 and Table S7, ESI $\dagger$ ) etc. Then the catalytic activity of the $\mathrm{Ni}_{0.7} \mathrm{Co}_{1.3} \mathrm{P} / \mathrm{GO}$ in the hydrolysis of $\mathrm{AB}$ was evaluated under the same conditions. Control experiments showed that pure GO has no catalytic activity for $\mathrm{AB}$ hydrolysis, while the $\mathrm{Ni}_{0.7} \mathrm{Co}_{1.3} \mathrm{P} / \mathrm{GO}$ sample exhibited exceedingly higher catalytic performance compared to the single $\mathrm{Ni}_{0.7} \mathrm{Co}_{1.3} \mathrm{P}$ alone. The dramatically improved activity can be attributed to the good dispersion and hence the enlarged surface area of nanoparticles on the GO surface with good electrical activity, therefore, creating an additional synergistic effect between the connection. ${ }^{55-58}$ The interaction between $\mathrm{Ni}_{0.7} \mathrm{Co}_{1.3} \mathrm{P}$ and GO was confirmed by XAFS (Fig. 6). The rising edge of the $\mathrm{Ni}_{0.7} \mathrm{Co}_{1.3} \mathrm{P} / \mathrm{GO}$ sample shifts to a higher energy, implying slight electron transfer may occur from $\mathrm{Ni}_{0.7} \mathrm{Co}_{1.3} \mathrm{P}$ to the $\mathrm{GO}$, which was also corroborated by XPS (Fig. S21, ESI $\dagger$ ). Both experimental results indicate a bonding relationship between the two materials.
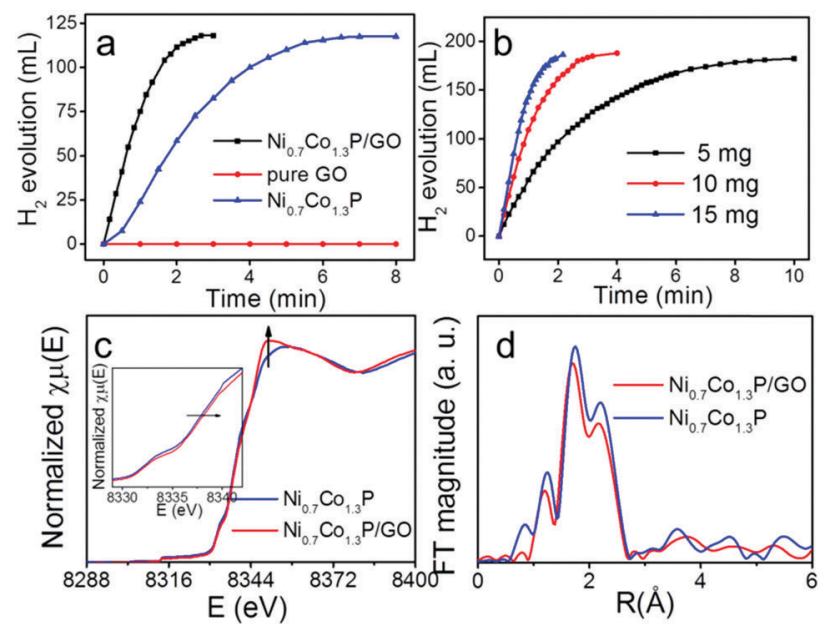

Fig. 6 (a) Stoichiometric hydrogen evolution in $0.5 \mathrm{M} \mathrm{NaOH}$ solution $(5 \mathrm{~mL})$ containing $1.62 \mathrm{mmol} \mathrm{AB}$ catalyzed by pure $\mathrm{GO}, \mathrm{Ni}_{0.7} \mathrm{Co}_{1.3} \mathrm{P}$ and the $\mathrm{Ni}_{0.7} \mathrm{Co}_{1.3} \mathrm{P} / \mathrm{GO}$ nanohybrid at $298 \mathrm{~K}$. (b) The relationship between the $\mathrm{H}_{2}$ generation rate and various amounts of the $\mathrm{Ni}_{0.7} \mathrm{CO}_{1.3} \mathrm{P} / \mathrm{GO}$ nanocatalyst. (c) Ni K-edge XANES spectra and (d) the corresponding FT curves of the $\mathrm{Ni}_{0.7} \mathrm{CO}_{1.3} \mathrm{P} \mathrm{NPS}$ and $\mathrm{Ni}_{0.7} \mathrm{Co}_{1.3} \mathrm{P} / \mathrm{GO}$ nanohybrid.

The stability of the $\mathrm{Ni}_{0.7} \mathrm{Co}_{1.3} \mathrm{P} / \mathrm{GO}$ sample is also probed by the recycling experiment. As shown in Fig. S23 (ESI $\dagger$ ), the $\mathrm{Ni}_{0.7} \mathrm{Co}_{1.3} \mathrm{P} / \mathrm{GO}$ sample maintains $93.0 \%$ of its initial activity after 5 cycles. It is worth mentioning that the recovered sample in the second cycle demonstrates an extraordinary activity with a TOF value of about $153.9 \operatorname{mol}_{\left(\mathrm{H}_{2}\right)} \operatorname{mol}_{\left(\mathrm{Ni}_{0.7} \mathrm{Co}_{1.3} \mathrm{P}\right)}{ }^{-1} \min ^{-1}$, which is much higher than that in the first cycle (TOF = $\left.93.3 \operatorname{mol}_{\left(\mathrm{H}_{2}\right)} \operatorname{mol}_{\left(\mathrm{Ni}_{0.7} \mathrm{Co}_{1.3} \mathrm{P}\right)}{ }^{-1} \mathrm{~min}^{-1}\right)$. Such a phenomenon is also observed for the pure $\mathrm{Ni}_{0.7} \mathrm{Co}_{1.3} \mathrm{P}$ sample and for other metal phosphides reported in our previous studies. ${ }^{32,59}$ This can be reasonably explained by the in situ reduction of some surface oxidized Ni-Co-P species in this reductive $\mathrm{NH}_{3} \mathrm{BH}_{3}$ system. As far as we know, this achieved TOF of 153.9 (109.4 based on the total mole number of metal) represents one of the highest values ever reported for all noble-metal-free based catalysts (Table S8, ESI $\dagger$ ).

\section{Conclusions}

In summary, we have successfully achieved a feasible, viable and scalable way to synthesize Co-doped nickel phosphide NPs and their nanohybrid with graphene oxide (GO) as excellent catalysts for hydrolysis of $\mathrm{AB}$. Benefitting from the ternary $\mathrm{Ni}-\mathrm{Co}-\mathrm{P}$ synergistic effect, high dispersibility, improved surface area and the interfacial interaction between $\mathrm{Ni}_{0.7} \mathrm{Co}_{1.3} \mathrm{P}$ and GO, the $\mathrm{Ni}_{0.7} \mathrm{Co}_{1.3} \mathrm{P} / \mathrm{GO}$ shows a high initial turnover frequency (TOF) of up to $153.9 \operatorname{mol}_{\left(\mathrm{H}_{2}\right)} \operatorname{mol}_{\left(\mathrm{Ni}_{0.7} \mathrm{Co}_{1.3} \mathrm{P}\right)}{ }^{-1} \mathrm{~min}^{-1}$ at ambient temperature, which is an unprecedented value higher than those ever reported for noble-metal-free catalytic systems, and a good sustainability maintaining $93.0 \%$ activity after 5 cycles. The promotion is rationalized through Density Functional Theory indicating that hydroxyl activation of the $\mathrm{AB}$ bond is enhanced when Co is present. These findings not only enrich 
the family of noble-metal-free catalysts for $\mathrm{AB}$ hydrolysis, but also provide significant and promising insights into modulating the electronic structures of metal phosphides for hydrogen storage and related applications.

\section{Acknowledgements}

The financial support from the National Key Basic Research Program of China (973 Program 2013CB834800 and 2013CB632403) and the Strategic Priority Research Program of the Chinese Academy of Sciences (XDB17030300) are deeply acknowledged. This work was partially supported by the Natural Science Foundation of China (21371175) and CAS-Croucher Funding Scheme for Joint Laboratories. Y. C. is thankful of support from the Chinese Academy of Sciences (100 Talents Program). Q. L. and N. L. are grateful to MINECO (CTQ2015-68770-R) for financial support and to the Centro de Supercomputación y Visualización de Madrid, Universidad Politécnica de Madrid for providing the computational resources through the BSC-RES. We also thank BSRF for synchrotron beamtime.

\section{Notes and references}

1 Q.-L. Zhu and Q. Xu, Energy Environ. Sci., 2015, 8, 478-512.

2 Ö. Metin, V. Mazumder, S. Özkar and S. H. Sun, J. Am. Chem. Soc., 2010, 132, 1468-1469.

3 F. A. de Bruijn, ChemSusChem, 2008, 1, 782-783.

4 J. Yang, A. Sudik, C. Wolverton and D. Siegel, Chem. Soc. Rev., 2010, 39, 656-675.

5 J. Wang, X. B. Zhang, Z. L. Wang, L. M. Wang and Y. Zhang, Energy Environ. Sci., 2012, 5, 6885-6888.

6 J. Wang, Y. L. Qin, X. Liu and X. B. Zhang, J. Mater. Chem., 2012, 22, 12468-12470.

7 J. M. Yan, X. B. Zhang, T. Akita, M. Haruta and Q. Xu, J. Am. Chem. Soc., 2010, 132, 5326-5327.

8 J. M. Yan, X. B. Zhang, H. Shioyama and Q. Xu, J. Power Sources, 2010, 195, 1091-1094.

9 J. M. Yan, X. B. Zhang, S. Han, H. Shioyama and Q. Xu, J. Power Sources, 2009, 194, 478-481.

10 S. K. Singh, A. K. Singh, K. Aranishi and Q. Xu, J. Am. Chem. Soc., 2011, 133, 19638-19642.

11 H.-L. Jiang, S. K. Singh, J.-M. Yan, X.-B. Zhang and Q. Xu, ChemSusChem, 2010, 3, 541-549.

12 Q. Xu and M. Chandra, J. Alloys Compd., 2007, 446-447, 729-732.

13 W. Chen, J. Ji, X. Duan, G. Qian, P. Li, X. Zhou, D. Chen and W. Yuan, Chem. Commun., 2014, 50, 2142-2144.

14 M. Zahmakiran and S. Özkar, Top. Catal., 2013, 56, 1171-1183.

15 M. Rakap, Appl. Catal., A, 2014, 478, 15-20.

16 S. Wang, D. Zhang, Y. Ma, H. Zhang, J. Gao, Y. Nie and X. Sun, ACS Appl. Mater. Interfaces, 2014, 6, 12429-12435.

17 T. J. Clark, G. R. Whittell and I. Manners, Inorg. Chem., 2007, 46, 7522-7527.

18 J.-M. Yan, X.-B. Zhang, S. Han, H. Shioyama and Q. Xu, Inorg. Chem., 2009, 48, 7389-7393.

19 Z.-H. Lu, H.-L. Jiang, M. Yadav, K. Aranishi and Q. Xu, J. Mater. Chem., 2012, 22, 5065-5071.
20 X. Ma, Y.-X. Zhou, H. Liu, Y. Li and H.-L. Jiang, Chem. Commun., 2016, 52, 7719-7722.

21 Q. Xu and M. Chandra, J. Power Sources, 2006, 163, 364-370.

22 J.-M. Yan, X.-B. Zhang, S. Han, H. Shioyama and Q. Xu, Angew. Chem., Int. Ed., 2008, 47, 2287-2289.

23 K. Feng, J. Zhong, B. Zhao, H. Zhang, L. Xu, X. H. Sun and S.-T. Lee, Angew. Chem., Int. Ed., 2016, 55, 11950-11954.

24 M. Mahyari and A. Shaabani, J. Mater. Chem. A, 2014, 2, 16652-16659.

25 J. Hu, Z. Chen, M. Li, X. Zhou and H. Lu, ACS Appl. Mater. Interfaces, 2014, 6, 13191-13200.

26 Y.-Z. Chen, Q. Xu, S.-H. Yu and H.-L. Jiang, Small, 2015, 11, 71-76.

27 H. Zhang, X. Wang, C. Chen, C. An, Y. Xu, Y. Huang, Q. Zhang, Y. Wang, L. Jiao and H. Yuan, Int. J. Hydrogen Energy, 2015, 40, 12253-12261.

28 D. R. Weinberg, C. J. Gagliardi, J. F. Hull, C. F. Murphy, C. A. Kent, B. C. Westlake, A. Paul, D. H. Ess, D. G. McCafferty and T. J. Meyer, Chem. Rev., 2012, 112, 4016-4093.

29 J. Q. Tian, Q. Liu, A. M. Asiri and X. P. Sun, J. Am. Chem. Soc., 2014, 136, 7587-7590.

30 Q. Liu, J. Q. Tian, W. Cui, P. Jiang, N. Y. Cheng, A. M. Asiri and X. P. Sun, Angew. Chem., Int. Ed., 2014, 53, 6710-6714.

31 S. Cao, Y. Chen, C. J. Wang, P. He and W. F. Fu, Chem. Commun., 2014, 50, 10427-10429.

32 C. Y. Peng, L. Kang, S. Cao, Y. Chen, Z. S. Lin and W. F. Fu, Angew. Chem., Int. Ed., 2015, 54, 15725-15729.

33 Z. Wang, X. Q. Cao, D. Liu, S. Hao, G. Du, A. M. Asiri and X. P. Sun, Chem. Commun., 2016, 52, 14438-14441.

34 W. Li, X. F. Gao, X. G. Wang, D. Xiong, P. Huang, W. G. Song, X. H. Bao and L. F. Liu, J. Power Sources, 2016, 330, 156-166.

35 W. Li, D. Xiong, X. F. Gao, W. G. Song, F. Xia and L. F. Liu, Catal. Today, 2017, 1, 122-129.

36 J. Q. Li, M. Yan, X. M. Zhou, Z.-Q. Huang, Z. M. Xia, C.-R. Chang, Y. Y. Ma and Y. Q. Qu, Adv. Funct. Mater., 2016, 37, 6785-6796.

37 J. Yu, Q. Q. Li, Y. Li, C. Y. Xu, L. Zhen, V. P. David and J. S. Wu, Adv. Funct. Mater., 2016, 26, 7644-7651.

38 P. Zhang, Y. Chen, M. Wang, Y. Yang, J. Jiang, B. Zhang, L. Duan, Q. Daniel, F. Li and L. C. Sun, J. Mater. Chem. A, 2017, 5, 7564-7570.

39 W. Y. Chen, D. Li, Z. J. Wang, G. Qian, Z. J. Sui, X. Z. Duan, X. G. Zhou, I. Yeboah and D. Chen, AIChE J., 2017, 1, 60-65.

40 G. Chen, S. Desinan, R. Rosei, F. Rosei and D. Ma, Chem. - Eur. J., 2012, 18, 7925-7930.

41 N. Mohajeri, A. T-Raissi and O. Adebiyi, J. Power Sources, 2007, 167, 482-485.

42 Y. K. Lee and S. T. Oyama, J. Catal., 2006, 239, 376-389.

43 T. Kawai, K. K. Bando, Y. K. lee, S. T. Oyama, W. J. Chun and K. Asakura, J. Catal., 2006, 241, 20-24.

44 H.-R. Seo, K.-S. Cho and Y.-K. Lee, Mater. Sci. Eng., B, 2011, 176, 132-140.

45 S. T. Oyama, T. Gott, K. AsaKura, S. TakaKusagi, K. Miyazaki, Y. Koike and K. K. Bando, J. Catal., 2009, 268, 209-222.

46 Y. Chen, C. Li, J. Zhou, S. Zhang, D. Rao, S. He, M. Wei, D. G. Evans and X. Duan, ACS Catal., 2015, 5, 5756-5765. 
47 L. Zhou, M. Shao, C. Zhang, J. Zhao, S. He, M. Rao, M. Wei, D. G. Evans and X. Duan, Adv. Mater., 2016, 1604080.

48 K. Xu, H. Ding, H. F. Lv, P. Z. Chen, X. Lu, H. Cheng, T. Zhou, S. Liu, X. J. Wu, C. Z. Wu and Y. Xie, Adv. Mater., 2016, 28, 3326-3332.

49 J. P. Perdew and K. Burke; M. Ernzerhof, Phys. Rev. Lett., 1996, 77, 3865-3868.

50 M. Garcia-Ratés and N. López, J. Chem. Theory Comput., 2016, 12, 1331-1341.

51 T. Maiyalagan and V. S. Saji, Electrocatalysts for Low Temperature Fuel Cells: Fundamentals and Recent Trends, John Wiley \& Sons, 2017.

52 G. Henkelman, A. Arnaldsson and H. Jónsson, Comput. Mater. Sci., 2006, 36, 254.
53 B. Molina Concha, M. Chatenet, F. Maillard, E. A. Ticianelli, F. H. B. Lima and R. B. de Lima, Phys. Chem. Chem. Phys., 2010, 12, 11507-11516.

54 B. Molina Concha, M. Chatenet, F. H. B. Lima and E. A. Ticianelli, Electrochim. Acta, 2013, 89, 607-615.

55 P. Xi, F. Chen, G. Xie, C. Ma, H. Liu, C. Shao, J. Wang, Z. Xu, $\mathrm{X}$. Xu and Z. Zeng, Nanoscale, 2012, 4, 5597-5601.

56 L. Yang, N. Cao, C. Du, H. Dai, K. Hu, W. Luo and G. Cheng, Mater. Lett., 2014, 115, 113-116.

57 K. Gungörmez and Ö. Metin, Appl. Catal., A, 2015, 494, 22-28.

58 N. S. Ciftci and Ö. Metin, Int. J. Hydrogen Energy, 2014, 39, 18863-18870.

59 Z. C. Fu, Y. Xu, S. L. F. Chan, W. Wang, F. Li, F. Liang, Y. Chen, Z. S. Lin, W. F. Fu and C.-M. Che, Chem. Commun., 2017, 53, 705-708. 